7. Reprod. Fert. (1974) 39, 111-113

\title{
INCREASING COPULATORY BEHAVIOUR IN AGEING MALE RATS WITH AN ELECTRICAL STIMULUS
}

\author{
O. P. SHARMA* AND R. L. HAYS \\ Department of Dairy Science, \\ University of Illinois, Urbana, Illinois 61801, U.S.A.
}

(Received 31st December 1973)

\begin{abstract}
Summary. Electrical stimulation of 10 to $15 \mathrm{~V}$ for 1 to $2 \mathrm{sec}$ applied to the dorso-lumbar region of ageing male rats significantly increased the number of times oestrous females were mounted.
\end{abstract}

In our laboratory, young male Holtzman rats have good libido but this decreases with age until some males will refuse to mate a receptive female. After accumulating data on a male's fertility and on his offspring, this lack of libido is a hindrance in certain types of experiments. One of the authors noted that when he pinched old males to wake them up or to make them more active, they frequently mated very quickly. In searching for a satisfactory stimulus for ageing males, it was noted that Barfield \& Sachs (1968) augmented the sexual activity of male rats with electrical shock. The present report concerns the effect of electrical stimulation of ageing male rats on their frequency of copulation.

Eighteen albino male Holtzman rats aged 14 to 18 months and weighing approximately $650 \mathrm{~g}$, which had had good libido and were fertile but which now had a reduced interest in receptive females, were used. They were stimulated in the shaved dorso-lumbar region with an electrical shock of 10 to $15 \mathrm{~V}$ for 1 to $2 \mathrm{sec}$ with an electroejaculation apparatus using electrodes $5 \mathrm{~mm}$ apart. The tests were made between 22.00 and 02.00 hours by placing an untreated female in oestrus in the cage where the male was housed.

In the first experiment, ten males were tested as follows: 3 min with a receptive female, then $3 \mathrm{~min}$ rest with no female present, then 3 min with a receptive female but stimulated electrically if no interest in the female was shown, and then $3 \mathrm{~min}$ rest. This was repeated three times in succession.

In Exp. 2, eight 14- to 16-month-old males were placed with receptive females for $30 \mathrm{~min}$ with intermittent electrical stimulation. On another day, they were placed with a receptive female but received no electrical stimulation. For four of the eight rats, the experimental period was first, and for the remaining four, the control period was first.

The differences in the number of mounts of the two groups was significant in Exp. $1(P>0.05)$ (Table 1) and in Exp. $2(P>0.005)$ (Table 2). In Exp. 2,

* Present address: Department of Veterinary Science, University of Kentucky, Lexington, Kentucky, U.S.A. 
Table 1. Effect of electrical stimulation of the dorso-lumbar region on the copulatory behaviour of ageing males (Exp. 1)

\begin{tabular}{c|c|c|c}
\hline \multirow{2}{*}{ Rat no. } & \multicolumn{3}{|c}{ No. of mounts* } \\
\cline { 2 - 4 } & $\begin{array}{c}\text { With } \\
\text { stimulation }\end{array}$ & $\begin{array}{c}\text { Without } \\
\text { stimulation }\end{array}$ & $\begin{array}{c}\text { Ejaculation } \\
\text { time (min) }\end{array}$ \\
\hline 1 & 9 & 2 & $-\dagger$ \\
2 & 8 & 1 & - \\
3 & 14 & 3 & - \\
4 & 19 & 12 & 21 \\
5 & 11 & 4 & 18 \\
6 & 15 & 12 & - \\
7 & 11 & 2 & - \\
8 & 13 & 7 & 25 \\
9 & 8 & 5 & 5 \\
10 & 18 & 53 & \\
Total & 126 & 53 & \\
* In three 3-min periods within 33 min. \\
† Indicates that no ejaculation occurred during any \\
mount in the 33 min.
\end{tabular}

seven males ejaculated during the stimulation period but only four ejaculated in the control period. The time to ejaculation also appeared to be shorter during stimulation. When ejaculation occurred, the female became pregnant and gave birth to normal young. The number of young in the litter appeared to be normal.

The finding that a non-sexual stimulus increased the sexual activity of ageing male rats is in agreement with the results of Barfield \& Sachs (1968) who found that electrical stimuli increased the sexual activity of adult male rats and Larsson (1963) who reported that handling increased the sexual activity of ageing male rats.

Other non-specific stimuli might increase the sexual activity in ageing rats which have a reduced libido and in males of other species.

Table 2. Effect of electrical stimulation of dorso-lumbar region on the copulatory behaviour of ageing males (Exp. 2)

\begin{tabular}{c|c|c}
\hline \multirow{2}{*}{ Rat no. } & \multicolumn{2}{|c}{ No. of mounts in 30 min } \\
\cline { 2 - 3 } & With stimulation & Without stimulation \\
\hline 1 & $46(30)$ & 11 \\
2 & $32(35)$ & 0 \\
3 & $38(27)$ & $30(30)$ \\
4 & $29(15)$ & $29(21 \cdot 5)$ \\
5 & $30(17)$ & $26(25)$ \\
6 & 17 & 0 \\
7 & $41(25)$ & 13 \\
8 & $31(20)$ & $25(30)$ \\
Total & 274 & 134 \\
\hline
\end{tabular}

Numbers in parentheses indicate the time (in min) at which the ejaculation occurred. 
It is possible that as the male rat ages, the threshhold for sexual arousal or sustained sexual arousal is raised and that electrical stimulation lowers the threshhold or that there is a summation of stimuli resulting in increased sexual activity.

This research was supported in part by funds from the Illinois Agricultural Experiment Station.

\section{REFERENGES}

BARFIELD, R. J. \& SACHS, B. D. (1968) Sexual behavior: stimulation by painful electric shock to skin in male rats. Science, N.Y. 161, 392.

Larsson, K. (1963) Non-specific stimulation and sexual behavior in the male rat. Behaviour, 20, 110. 